\title{
Procalcitonin and lung ultrasound algorithm to diagnose severe pneumonia in critical paediatric patients (PROLUSP study). A randomised clinical trial
}

\author{
Javier Rodríguez-Fanjul' ${ }^{1}$, Carmina Guitart ${ }^{2,3}$, Sara Bobillo-Perez ${ }^{2,3}$, Mònica Balaguer ${ }^{2 *}$ (1) and lolanda Jordan ${ }^{2,3,4}$
}

\begin{abstract}
Background: Lung ultrasound (LUS) in combination with a biomarker has not yet been studied. We propose a clinical trial where the primary aims are: 1 . To assess whether an algorithm with LUS and procalcitonin (PCT) may be useful for diagnosing bacterial pneumonia; 2. To analyse the sensitivity and specificity of LUS vs chest X-ray (CXR).

Methods/design: A 3-year clinical trial. Inclusion criteria: children younger than 18 years old with suspected pneumonia in a Paediatric Intensive Care Unit. Patients will be randomised into two groups: Experimental Group: LUS will be performed as first lung image. Control Group: CXR will be performed as first pulmonary image. Patients will be classified according to the image and the PCT: a) $P C T<1 \mathrm{ng} / \mathrm{mL}$ and LUS/CXR are not suggestive of bacterial pneumonia (BN), no antibiotic will be prescribed; b) LUS/CXR are suggestive of BN, regardless of the $P C T$, antibiotic therapy is recommended; c) LUS/CXR is not suggestive of BN and PCT $>1 \mathrm{ng} / \mathrm{mL}$, antibiotic therapy is recommended.
\end{abstract}

Conclusion: This algorithm will help us to diagnose bacterial pneumonia and to prescribe the correct antibiotic treatment. A reduction of antibiotics per patient, of the treatment length, and of the exposure to ionizing radiation and in costs is expected.

Trial registration: NCT04217980.

\section{Background}

Pneumonia is responsible for more than 2 million child deaths around the world; it is the leading cause of childhood morbidity and mortality [1]. Moreover, severe lower respiratory infection is the most common cause of admission to paediatric intensive care units (PICUs) [2]. Around $60-70 \%$ of these have a viral etiology [3]. For physicians, it is important to differentiate between viral and bacterial infection because each entails a different

\footnotetext{
* Correspondence: mbalaguer@sjdhospitalbarcelona.org

${ }^{2}$ Paediatric Intensive Care Unit, Hospital Sant Joan de Déu, University of Barcelona, Po Sant Joan de Déu, 2, 08950 Esplugues, Barcelona, Spain Full list of author information is available at the end of the article
}

therapeutic approach (whether antibiotics are indicated and the treatment duration), a different prognosis in the short and long term, and requires a different hospital isolation policy $[4,5]$. It is challenging to rule whether a case of pneumonia is viral or bacterial in origin [6-8]. Clinical symptoms are similar and although conventional chest radiographs (CXR) have traditionally been considered the best diagnostic option [9], the specificity of CXR for determining bacterial etology remains low. Chest computed tomography may detect smaller pulmonary consolidations not visible via CXR, but it cannot be routinely performed on critically ill patients due to cost, exposure to radiation, and transportation risk [9].

\section{$\triangle B M C$}

(c) The Author(s). 2020 Open Access This article is licensed under a Creative Commons Attribution 4.0 International License, which permits use, sharing, adaptation, distribution and reproduction in any medium or format, as long as you give appropriate credit to the original author(s) and the source, provide a link to the Creative Commons licence, and indicate if changes were made. The images or other third party material in this article are included in the article's Creative Commons licence, unless indicated otherwise in a credit line to the material. If material is not included in the article's Creative Commons licence and your intended use is not permitted by statutory regulation or exceeds the permitted use, you will need to obtain permission directly from the copyright holder. To view a copy of this licence, visit http://creativecommons.org/licenses/by/4.0/. The Creative Commons Public Domain Dedication waiver (http://creativecommons.org/publicdomain/zero/1.0/) applies to the data made available in this article, unless otherwise stated in a credit line to the data. 
Therefore, there is a need to have an examination tool that can be used at the patient's bedside and which is easily reproducible to help detect lung consolidations. LUS has recently emerged as a radiation-free technique; it is non-invasive, with a high interobserver [10] agreement for lung pathologies such as consolidation [11], pleural effusion [12], interstitial syndrome [13], and pneumothorax [14]. To determine the etiology, conventional microbiology tests such as blood culture, pleural aspiration, and bronchoalveolar lavage are usual practices, but some of these are invasive, may not detect all etiologies [15], and the results may not be immediate.

Besides this, the use of biomarkers such as procalcitonin (PCT) has become more widespread during the past 10 years, helping clinicians diagnose bacterial etiology, especially in patients who have only had a fever for a few hours or those admitted to intensive care units [16-20]. The use of PCT has allowed for a decrease in antibiotic prescription [21, 22], even in nosocomial and community pneumonia $[23,24]$. Despite its role in the diagnosis of pneumonia, PCT values without any other tests may not be a complete diagnostic biomarker for pneumonia.

Quality of care is defined by the World Health Organization as medical care in which the patient is diagnosed and treated correctly, according to current medical knowledge (scientific and technical quality), and to their biological factors (optimal state of health to attain), with a minimum cost (efficiency), minimum possible exposure to risk for more harm, and maximum patient satisfaction [25]. At the hospital level, a quality assurance plan should include different levels of action. The first step is level 1 of quality promotion, which requires institutional support and the availability of clinical and quality protocols. The second step is the research level: descriptive studies for detecting and quantifying a specific situation or health issue, and the use of databases or specific studies to evaluate health services, among others.

Therefore, we propose this clinical trial, based on combining LUS and PCT in an algorithm with the aim to improve quality of care in children with pneumonia in a PICU. We hypothesize that the diagnostic performance of LUS and PCT will be better than conventional CXR.

\section{Methods and design}

The study is designed as a randomized, blinded clinical trial of children with severe community or nosocomial pneumonia. It will be conducted at a single PICU at Sant Joan de Déu Hospital, a tertiary children's hospital in Barcelona. Period of recruitment and follow-up was from September 2017 to December 2019.

\section{Study aim}

Our primary goal is to improve the quality of care in children with suspected community or nosocomial pneumonia in a PICU.

The main objectives are:

1. To assess whether a diagnostic algorithm for pneumonia that combines LUS and PCT may be useful in indicating and determining the duration of antibiotic treatment.

2. To analyse the sensitivity and specificity of LUS, compared to CXR, for severe community or nosocomial pneumonia.

The secondary aims are:

1. To quantify the irradiation dose avoided using LUS to replace CXR, and to determine if there is an associated decrease in costs.

2. To analyse interobserver agreement in LUS

\section{Inclusion and exclusion criteria}

Inclusion: Children under 18 years old with suspected community pneumonia who require admission to the PICU or patients with suspected nosocomial pneumonia during their PICU stay.

Exclusion: Patients with underlying pathologies such as cystic fibrosis or who are immunocompromised. $\mathrm{Pa}$ tients who develop nosocomial pneumonia after being included in the study due to community pneumonia. $\mathrm{Pa}$ tients who have a CXR taken before being admitted to the PICU.

Withdrawal and abandonment criteria: Violation of study protocol, withdrawal of parental consent, death.

Patients withdrawing or with loss of protocol adherence will be excluded from the study.

\section{Definitions}

- Community pneumonia: Patients with compatible clinical suspicion (fever, cough, tachypnoea, shortness of breath, abnormal respiratory auscultation sounds, hypoventilation, tubular breath sounds, thoracic or abdominal pain), compatible CXR (lobar consolidation, airspace opacity, pleural effusion, bullae, etc.) or LUS, changes in blood with a C-reactive protein higher than $50 \mathrm{mg} / \mathrm{L}$ and/or PCT higher than $1 \mathrm{ng} / \mathrm{mL}$.

- Nosocomial pneumonia: Based on the Clinical Pulmonary Infection Score (CPIS) (Table 1).

- Ventilator-associated pneumonia: defined according to the Center for Disease Control criteria (CDC). 


\section{LUS procedure}

LUS will be performed by any of the 8 intensive care physicians who have received standard training in LUS (Winfocus PNCUS BL1P) and who have at least 3 years of experience using it. Team sessions focusing on the diagnosis of pneumonia with LUS will be repeated every 3 months to ensure quality and consistency in the LUS exam. The supplemental data included in the Shah et al. article will be used [26].

Subjects will be examined while they are in supine position. Imaging will be performed using a portable ultrasound device (Toshiba ${ }^{\circ}$ Xario 200). A $12-\mathrm{MHz}$ linear or a $5-\mathrm{MHz}$ convex probe will be used, depending on the weight or size of the patient. A scan will be taken systematically in 3 areas for each hemithorax (anterior, lateral, and posterior), according to international recommendations [27]. Each area will be examined longitudinally and transversally.

In each area the following will be evaluated [27]: Alines, B-lines (number and distance between them), lung sliding (M-mode), pleural space, lung consolidations, small subpleural consolidations, dynamic air bronchogram, vascular pattern, presence of lung point, and lung pulse.

The determination of a bacterial pneumonia ultrasound pattern will be based on the presence of lung consolidation with air bronchograms, which in initial stages are detected as small subpleural hypoechoic zones of less than $1 \mathrm{~cm}$ with bronchogram (not seen using conventional CXR) [28-31]. The determination of a viral pneumonia ultrasound pattern will be based on the presence of B-lines or coalescent B-lines with small subpleural consolidations of less than $1 \mathrm{~cm}$, without bronchogram $[32,33]$.

\section{Methodology}

The first thing to do will be to obtain consent from the parent(s) or legal guardian(s).

Patients who meet the inclusion criteria and sign the inform consent were randomly assigned to two groups using the "random" function in MS-Excel XP program. A binary series of random numbers were generated according to the procedure described by Friedman. To procure a similar number of patients in both groups, the procedure created the sequence through a balanced block sampling. The series of numbers were held by the principal investigator and depending on the number of the patient tit was be assigned to on or another group. A total of 8 physicians enrolled participants, and the principal investigator assigned participants to interventions, depending on the randomized list. (Fig. 1)

- Experimental Group 1: The paediatrician-researcher (PR) performs the LUS at admission/suspicion as the first lung image test. If the paediatrician assistant (PA) requires a CXR, it can be performed, but the PR will not see the CXR. Patients will be subdivided into 3 groups:

a. If PCT is $<1 \mathrm{ng} / \mathrm{mL}$ and LUS is not suggestive of bacterial pneumonia (normal or viral), the patient will not receive an antibiotic.

b. If LUS is suggestive of bacterial pneumonia, regardless of PCT value, an antibiotic will be recommended.

c. If LUS is not suggestive of bacterial pneumonia, but PCT values are $>1 \mathrm{ng} / \mathrm{mL}$, an antibiotic will be recommended to cover other infectious etiologies.

- Control Group 2: CXR will be performed as a first lung image test. Criteria to start an antibiotic will depend on the current unit protocol.

a. If PCT is $<1 \mathrm{ng} / \mathrm{mL}$ and CXR is not suggestive of bacterial pneumonia (normal or viral), the patient will not receive an antibiotic.

b. If CXR is suggestive of bacterial pneumonia, regardless of PCT value, an antibiotic will be recommended.

c. If CXR is not suggestive of bacterial pneumonia, but PCT value is $>1 \mathrm{ng} / \mathrm{mL}$, an antibiotic will be recommended to cover other infectious etiologies.

Radiological and ultrasound patterns will be classified as: pneumonia (viral or bacterial), atelectasis, or parapneumonic pleural effusion (Table 2).

LUS will be performed every day following admission and recorded and stored. LUS images will be later analysed by a paediatric radiologist who is an expert in LUS and who has not seen the initial assessment and CXR, in order to evaluate interobserver agreement. CXR will be also be reported on by a paediatric radiologist consultant who has not seen the other results.

\section{Outcomes}

The antibiotics protocol guided by LUS and PCT will be considered an improvement in the quality of care if a reduction in the prescription of antibiotics is observed, and also if there is a reduction in the number of days on antibiotics. Another primary outcome will be the increase in the sensitivity and specificity when diagnosing bacterial pneumonia using LUS. Secondary outcomes will be the reduction of the irradiation dose using the new protocol (with a reduction in economic costs as well), and a high LUS interobserver agreement.

\section{Data collection}

The study coordinator will register patients, verifying compliance with all the inclusion criteria. An external 
company will be appointed to monitor the study and ensure compliance with correct clinical practice principles (ICHE6). Once the notebooks are audited, they will be entered into a validated database, one with restricted access by user level, which is equipped with inconsistency detection filters, and which affords data traceability until the database is no longer needed.

Data access: All the physicians and clinical researchers involved in the study, the Ethics Committee, and the relevant health authorities will have access to the data.

\section{Sample size}

Sample size calculations will be performed using the statistical program Ene $2.0^{\circ}$. The main variable will be the existence of differences between CXR and LUS in patients with community pneumonia and nosocomial pneumonia. $\mathrm{H} 1$ will be considered as the existence of differences between LUS and CXR. An $80 \%$ power will be required to detect differences in the contrast of the null hypothesis H0: $\mathrm{p} 1=\mathrm{p} 2$, using a bilateral $\mathrm{X}^{2}$ test for two independent samples. If we consider a significance level of $5 \%$, it will be necessary to include 63 units in the control group and 63 units in the experimental group. A total of 126 patients will be included for community pneumonia. Twenty-eight patients per group will be included for nosocomial pneumonia; therefore, there will be 56 patients in total for this kind of pneumonia. After 12 months of recruitment, a preliminary analysis will be carried out to guarantee the safety of the patients. Respiratory infection represents around $30-70 \%$ of the PICU admissions, depending on the season. There will be an estimated 200-300 recruitable patients per year, so it is expected that the calculated sample size will be attainable.

\section{Statistical analysis}

Using the "Random" function of the MS-Excel XP" program, a binary series of random numbers will be generated, according to the procedure described by Friedman [34]. This procedure creates the sequence by means of balanced block sampling to ensure a similar number of patients in each group. The series of numbers will be in the possession of the PICU's head researcher. Depending on that number, each patient will be assigned to one group or the other. If a patient is randomized but does not complete the treatment, their data will not be analysed, and their random number will not be reused.

The categorical variables will be compared using the Chi-square test. The quantitative analysis will be compared using Student's t-test or the Mann-Whitney U test, depending on whether the sample follows a normal distribution or not. A multivariate logistic regression analysis will be performed on those variables with statistical significance or a clear tendency in the univariate analysis to detect which factors represent a protective factor or not, in terms of quality. The analysis of the interobserver agreement will be performed using Cronbach's alpha. A $p<0.05$ will be considered significant. The statistical program SPPS 20.0 will be used.

\section{Discussion}

Nowadays, care standards are focused on the quality of care. As the World Health Organization stipulates, the patient must be diagnosed and treated correctly. This clinical trial is focused on improving the quality of care for paediatric patients with suspected bacterial pneumonia. LUS has good diagnostic accuracy for pneumonia in children, even if the exam is performed by a nonexpert physician [35]. Our algorithm will help us to diagnose bacterial pneumonia accurately, and to prescribe the correct antibiotic treatment. A reduction in patients on antibiotics and in the number of days on antibiotics is expected. Secondarily, a reduction in exposure to ionizing radiation and in costs is expected.

For many years, LUS has been integrated into the management of critically ill paediatric and neonatal patients at our hospital. Some articles have been published by our group regarding the use of LUS in different pathologies, such as prematurity, pulmonary arterial hypertension, during the postoperative period after cardiopulmonary bypass, etc. [36-38]. For the application of this clinical trial, all the researchers will be intensivists who are experts in LUS, and regular internal training will be essential to guarantee objective results.

In addition, our group has extensive experience in the use of PCT for the diagnosis of bacterial infection in other medical situations, such as after cardiopulmonary bypass in children and new-borns [19, 39]. Furthermore, we have experience in PCT-guided antibiotic policy, with a reduction in the number of days on antibiotics without adverse events in children with nosocomial infections [40] and in children after cardiopulmonary bypass [22].

\section{Conclusion}

The use procalcitonin and lung ultrasound algorithm will help us diagnose bacterial pneumonia accurately and prescribe the correct antibiotic treatment. A reduction in patients on antibiotics and in a reduction in exposure to ionizing radiation and in costs is expected. This clinical trial is focused on improving the quality of care for paediatric patients with suspected bacterial pneumonia.

\section{Supplementary information}

Supplementary information accompanies this paper at https://doi.org/10. 1186/s12931-020-01476-Z.

Additional file 1 Supplemental Table 1. Clinical Pulmonary Infection Score. 
Additional file 2 Supplemental Table 2. Summary of the main findings using chest $X$-rays and lung ultrasound for diagnosing pneumonia.

Additional file 3 Supplemental Figure 1. Study protocol diagram.

\section{Abbreviations}

LUS: Lung ultrasound; PCT: Procalcitonin; CXR: Chest X-ray; BN: Bacterial pneumonia; PICU: Pediatric intensive care unit; CPIS: Clinical Pulmonary Infection Score; CDC: Center for Disease Control Criteria

\section{Acknowledgments}

Not applicable.

\section{Study limitations}

We expect that with the estimated number of patients, relatively high for a paediatric study, and the homogeneity of the patients suffering from this pathology, we will have sufficient statistical power to obtain reliable data. Another limitation could be that since ultrasound-based assessments are user-dependent, there could be interobserver variability. Thanks to the internal training program, we believe that this limitation will be minimized.

\section{Study status}

This protocol is for a study that it is ongoing, authors are still analysing data.

\section{Related articles}

No publications containing the results of this study have been already published neither submitted to any journal.

\section{Disclosure statement}

Authors disclose any potential financial or ethical conflicts of interest regarding the contents.

\section{Category of study}

Clinical trial, Trial Registration: NCT04217980.

What is the key message of your article?

We propose an algorithm to use in the diagnosis of pneumonia to improve the quality of care in paediatric critical care.

What does it add to the existing literature?

There are few papers about the use of lung ultrasound with pneumonia but, to our knowledge, this is the first clinical trial to assess the use of lung ultrasound and laboratory biomarkers to improve the diagnosis of bacterial pneumonia in critically ill children admitted to a paediatric intensive care unit.

What is the impact?

The algorithm should improve bacterial pneumonia diagnosis and therefore the treatment of either community-acquired or nosocomial pneumonia in patients with respiratory infection suspicion. The impact should be seen in reduction of antibiotic indication in patients with non-bacterial pneumonia, reduction of radiation given to paediatric patients and reduction costs of its technique.

\section{Authors' contributions}

All the authors contributed to the conception and design of the protocol, acquisition of data, analysis and interpretation of data; drafting the article and revising it critically for important intellectual content; and they approval the final version to be published.

\section{Funding}

This study has been financially supported by Official Grant from Spain Sanitary Ministerium. No other institutions have financed this research. This study has been funded by Instituto de Salud Carlos III through the project " PI16/01040" (Co-funded by European Regional Development Fund/European Social Fund "A way to make Europe"/"Investing in your future"). Project " PI16/01040", funded by Instituto de Salud Carlos III and co-funded by European Union (ERDF/ESF, "A way to make Europe"/"Investing in your future"). Funding: ISCIII ("PI16/01040"), co-funded by ERDF/ESF, "A way to make Europe"/"Investing in your future").

Availability of data and materials

Not applicable.

\section{Ethics approval and consent to participate}

The study will be conducted in accordance with the ICH CP (ICH E6 and ICH E11) and the Declaration of Helsinki. The protocol study was approved by the local Health Care Ethics Committee and the institutional review board of the Sant Joan de Déu Hospital. The identities of the patients will be kept confidential throughout the entire study. Complete filiation data and written consent will be kept in the researcher's file. The data obtained will be treated according to the Organic Law 3/2018 on Protection of Personal Data. According to this law, the personal data collected from the subjects will be only those necessary to fulfil the study's objectives. Study participants will have the right to access their personal data and to request its rectification or cancellation. Given that the patients included in the study will be minors or will be in critical condition, in all cases informed consent will be requested from the legal representatives of these patients.

\section{Consent for publication}

Not applicable.

\section{Competing interests}

The authors declare that they have no competing interests.

\section{Author details}

${ }^{1}$ Neonatal Intensive Care Unit, Department of Paediatrics, Hospital Germans Trias i Pujol, Autonomous University of Barcelona, Badalona, Spain. ${ }^{2}$ Paediatric Intensive Care Unit, Hospital Sant Joan de Déu, University of Barcelona, Po Sant Joan de Déu, 2, 08950 Esplugues, Barcelona, Spain. ${ }^{3}$ Immunological and Respiratory Disorders in the Paediatric Critical Patient Research Group, Institut de Recerca Sant Joan de Déu, University of Barcelona, Barcelona, Spain. ${ }^{4}$ Paediatric Infectious Diseases Research Group. Institut de Recerca Sant Joan de Déu, CIBERESP, Barcelona, Spain.

Received: 3 April 2020 Accepted: 29 July 2020

Published online: 08 October 2020

\section{References}

1. United Nations Children's Fund (UNICEF). Commiting to child survival: a promise renewed; 2014

2. Rhodes A, Evans LE, Alhazzani W, et al. Surviving sepsis campaign; 2017. Available from: http://content.wkhealth.com/linkback/openurl?sid=WKPTLP: landingpage\&an=00003246-900000000-96723.

3. Li Y, Liang $Y$, Ling $Y$, Duan $M$, Pan $L$, Chen $Z$. The spectrum of viral pathogens in children with severe acute lower respiratory tract infection: a 3-year prospective study in the pediatric intensive care unit. J Med Virol. 2019;91:1633-42.

4. JM M, PA P, SJ T, et al. Prospective multicenter study of viral etiology and hospital length of stay in children with severe bronchiolitis. Arch Pediatr Adolesc Med. 2012;166:700 Available from: http://archpedi.jamanetwork. com/article.aspx?doi=10.1001/archpediatrics.2011.1669.

5. Dellinger RP, Levy MM, Rhodes A, et al. Surviving sepsis campaign: international guidelines for management of severe sepsis and septic shock, 2012. Intensive Care Med. 2013;39:165-228.

6. Voiriot G, Visseaux B, Cohen J, et al. Viral-bacterial coinfection affects the presentation and alters the prognosis of severe communityacquired pneumonia. Crit Care. 2016;20:1-9. https://doi.org/10.1186/ s13054-016-1517-9.

7. Torres A, Chalmers JD, Dela Cruz CS, et al. Challenges in severe communityacquired pneumonia: a point-of-view review. Intensive Care Med. 2019;45: 159-71. https://doi.org/10.1007/s00134-019-05519-y.

8. Tramper-Stranders GA. Childhood community-acquired pneumonia: a review of etiology- and antimicrobial treatment studies. Paediatr Respir Rev. 2018;26:41-8. https://doi.org/10.1016/j.prrv.2017.06.013.

9. Self WH, Courtney DM, McNaughton CD, et al. High discordance of chest $\mathrm{x}$ ray and computed tomography for detection of pulmonary opacities in ED patients: implications for diagnosing pneumonia. Am J Emerg Med. 2013; 31(2):401-5. https://doi.org/10.1016/j.ajem.2012.08.041.

10. Gullett J, Donnelly JP, Sinert R, et al. Interobserver agreement in the evaluation of B-lines using bedside ultrasound. J Crit Care. 2015;30:1395-9. https://doi.org/10.1016/j.jcrc.2015.08.021.

11. Staub LJ, Biscaro RRM, Maurici R. Accuracy and applications of lung ultrasound to diagnose ventilator-associated pneumonia: a systematic review. J Intensive Care Med. 2018;33:447-55. 
12. Brogi E, Gargani L, Bignami E, et al. Thoracic ultrasound for pleural effusion in the intensive care unit : a narrative review from diagnosis to treatment. Crit Care. 2017;21:1-11.

13. Lui JK, Banauch Gl. Diagnostic bedside ultrasonography for acute respiratory failure and severe hypoxemia in the medical intensive care unit: basics and comprehensive approaches. J Intensive Care Med. 2017;32:355-72.

14. Raimondi F, Rodriguez Fanjul J, Aversa S, et al. Lung ultrasound for diagnosing pneumothorax in the critically ill neonate. J Pediatr. 2015;175: 74-78.e1.

15. Mackenzie G. The definition and classification of pneumonia. Pneumonia. 2016;8:1-5. https://doi.org/10.1186/s41479-016-0012-z.

16. Bobillo-Perez S, Rodríguez-Fanjul J, Jordan Gl. Is Procalcitonin useful in pediatric critical care patients. Biomark Insights. 2018;13:117727191879224 http://journals.sagepub.com/doi/10.1177/1177271918792244.

17. Eschborn S, Weitkamp JH. Procalcitonin versus C-reactive protein: review of kinetics and performance for diagnosis of neonatal sepsis. J Perinatol. 2019; 39:893-903. https://doi.org/10.1038/s41372-019-0363-4.

18. Memar MY, Varshochi M, Shokouhi B, Asgharzadeh M, Kafil HS. Procalcitonin: the marker of pediatric bacterial infection. Biomed Pharmacother. 2017;96: 936-43.

19. Bobillo Pérez S, Rodríguez-Fanjul J, García IJ, Hernando JM, Sanz MI. Procalcitonin is a better biomarker than C-reactive protein in newborns undergoing cardiac surgery: the PROKINECA study. Biomark Insights. 2016; 11:123-9.

20. Pepper DJ, Sun J, Rhee C, et al. Procalcitonin-guided antibiotic discontinuation and mortality in critically ill adults: a systematic review and meta-analysis. Chest. 2019;155:1109-18. https://doi.org/10.1016/j.chest.2018. 12.029.

21. Póvoa P, Martin-Loeches I, Ramirez P, et al. Biomarkers kinetics in the assessment of ventilator-associated pneumonia response to antibiotics results from the BioVAP study. J Crit Care. 2017;41:91-7. https://doi.org/10. 1016/j.jcrc.2017.05.007.

22. Bobillo-Perez S, Sole-Ribalta A, Balaguer M, et al. Procalcitonin to stop antibiotics after cardiovascular surgery in a pediatric intensive care unit-the PROSACAB study. PLOS One. 2019;14:e0220686. https://doi.org/10. 1371/journal.pone.0220686.

23. Akagi T, Nagata N, Wakamatsu K, et al. Procalcitonin-guided antibiotic discontinuation might shorten the duration of antibiotic treatment without increasing pneumonia recurrence. Am J Med Sci. 2019;358:33-44.

24. Ericksen RT, Guthrie C, Carroll T. The use of Procalcitonin for prediction of pulmonary bacterial coinfection in children with respiratory failure associated with viral bronchiolitis. Clin Pediatr (Phila). 2019;58:288-94.

25. McMillan TR, Hyzy RC. Bringing quality improvement into the intensive care unit. Crit Care Med. 2007;35:59-65.

26. Shah VP, Tunik MG, Tsung JW. Prospective evaluation of point-of-care ultrasonography for the diagnosis of pneumonia in children and young adults. JAMA Pediatr. 2013;167:119-25.

27. Volpicelli G, Elbarbary M, Blaivas M, et al. International evidence-based recommendations for point-of-care lung ultrasound. Intensive Care Med. 2012;38:577-91.

28. Balk DS, Lee C, Schafer J, et al. Lung ultrasound compared to chest X-ray for diagnosis of pediatric pneumonia: A meta-analysis. Pediatr Pulmonol. 2018; 53(8):1130-9.

29. Stadler JAM, Andronikou S, Zar HJ. Lung ultrasound for the diagnosis of community-acquired pneumonia in children. Pediatr Radiol. 2017:47:1412-9.

30. Llamas-Álvarez AM, Tenza-Lozano EM, Latour-Pérez J. Accuracy of lung ultrasonography in the diagnosis of pneumonia in adults: systematic review and meta-analysis. Chest. 2017;151:374-82. https://doi.org/10.1016/j.chest. 2016.10.039.

31. Zhou J, Song J, Gong S, et al. Lung ultrasound combined with procalcitonin for a diagnosis of ventilator-associated pneumonia. Respir Care. 2019;64: 519-27.

32. Varshney T, Mok E, Shapiro AJ, Li P, Dubrovsky AS. Point-of-care lung ultrasound in young children with respiratory tract infections and wheeze. Emerg Med J. 2016:33:603-10.

33. Supino MC, Buonsenso D, Scateni S, et al. Point-of-care lung ultrasound in infants with bronchiolitis in the pediatric emergency department: a prospective study. Eur J Pediatr. 2019;178:623-32.

34. Skillings JH, Mack GA. On the use of a friedman-type statistic in balanced and unbalanced block designs. Technometrics. 1981;23:171-7.
35. Pereda MA, Chavez MA, Hooper-Miele CC, et al. Lung ultrasound for the diagnosis of pneumonia in children: a meta-analysis. Pediatrics. 2015;135: 714-22.

36. del Rey Hurtado de Mendoza B, Sánchez-de-Toledo J, Bobillo Perez S, Girona M, Balaguer Gargallo M, Rodríguez-Fanjul J. Lung ultrasound to assess the etiology of persistent pulmonary hypertension of the newborn (LUPPHYN study): a pilot study. Neonatology. 2019:1-7 https://www.karger. com/Article/FullText/499047.

37. Rodríguez-Fanjul J, Balcells C, Aldecoa-Bilbao V, Moreno J, Iriondo M. Lung ultrasound as a predictor of mechanical ventilation in neonates older than 32 weeks. Neonatology. 2016;110:198-203.

38. Raimondi F, Yousef N, Rodriguez Fanjul J, et al. A multicenter lung ultrasound study on transient tachypnea of the neonate. Neonatology. 2019;115:263-8.

39. Garcia IJ, Gargallo MB, Torné EE, et al. Procalcitonin: a useful biomarker to discriminate infection after cardiopulmonary bypass in children. Pediatr Crit Care Med. 2012;13:441-5 http://content.wkhealth.com/linkback/ openurl?sid=WKPTLP:landingpage\&an=00130478-201207000-00011.

40. Launes C, Esteban E, Balaguer M, Alsina M, Cambra FJ, Jordan I. Procalcitonin-guidance reduces antibiotic exposure in children with nosocomial infection (PRORANI). J Inf Secur. 2016;72:250-3.

\section{Publisher's Note}

Springer Nature remains neutral with regard to jurisdictional claims in published maps and institutional affiliations.
Ready to submit your research? Choose BMC and benefit from:

- fast, convenient online submission

- thorough peer review by experienced researchers in your field

- rapid publication on acceptance

- support for research data, including large and complex data types

- gold Open Access which fosters wider collaboration and increased citations

- maximum visibility for your research: over $100 \mathrm{M}$ website views per year

At BMC, research is always in progress.

Learn more biomedcentral.com/submissions 